\title{
Evaluation of a Failed Heart Valve Bioprosthesis Using Microcomputed Tomography
}

\author{
DOI: $10.17691 / \mathrm{stm} 2017.9 .3 .02$
}

Received January 20, 2017

E.A. Ovcharenko, PhD, Senior Researcher, Laboratory of New Biomaterials, Experimental

and Clinical Cardiology Department;

K.U. Klyshnikov, Researcher, Laboratory of New Biomaterials, Experimental and Clinical Cardiology Department';

T.V. Glushkova, PhD, Researcher, Laboratory of New Biomaterials, Experimental and Clinical Cardiology Department';

A.V. Batranin, Research Engineer2;

M.A. Rezvova, Junior Researcher, Laboratory of New Biomaterials, Experimental and Clinical Cardiology Department';

Y.A. Kudryavtseva, DSc, Head of Experimental and Clinical Cardiology Department';

L.S. Barbarash, MD, DSc, Professor, Academician of the Russian Academy of Sciences, Chief Researcher ${ }^{1}$

${ }^{1}$ Research Institute for Complex Issues of Cardiovascular Diseases, 6 Sosnovy blvd., Kemerovo, 650002,

Russian Federation;

${ }^{2}$ National Institute "Tomsk Polytechnic University", 30 Lenin Avenue, Tomsk, 634050, Russian Federation

The aim of the investigation was to assess the capabilities of microcomputed tomography with subsequent image analysis of explanted failed biological heart valves prostheses.

Materials and Methods. The study is based on the explanted (after 5-year functioning) xenopericardial biological prosthesis UniLine (Russia). Microcomputed tomography with subsequent post-processing and image analysis was performed using the experimental tomographic scanner Orel-MT (Russia). Histological examination using alizarin red staining was performed for reference assessment of the structural changes of the biological tissue during bioprosthesis functioning.

Results. The analysis of gray and pseudo-color tomograms revealed the localization of most dense calcifications in the leaflets and covering tissues of a bioprosthesis. The study of the deformed bioprosthetic elements showed significant changes in the inclination angle of the prosthesis frame racks, the curvature radius and angle of deflection of the leaflets. A qualitative assessment of the morphology of calcifications was made on the basis of volume rendering, the average projection and maximum intensity projection. The 3D model triangular mesh of the failed prosthesis was constructed by the tomogram segmentation followed by quantitative analysis of tissue degeneration. The morphology of the calcifications obtained the microcomputed tomography was confirmed by histological examination findings.

Conclusion. Microcomputed tomography enables to perform qualitative and quantitative assessment of biological tissue calcification and bioprosthesis deformation. The findings offer the opportunity to carry out batch quantitative processing of the reconstructed models.

Key words: microcomputed tomography; heart valve bioprostheses; bioprosthetic tissue degeneration; bioprosthesis calcification.

Every year about 12,000 heart valve replacements are performed in Russia, 2,400 among them are biological prostheses, and up to $26.4 \%$ patients undergo a redo heart valve replacement due to a failed leaflet apparatus [1]. Up to $90 \%$ failed bioprostheses are due to a primary tissue failure caused by a number of factors, tissue structural degradation and calcification being the main factors $[2,3]$. Due to the fact that a number of acquired and congenital valvular heart diseases is growing, a number of operations using biological prostheses is increasing steadily [1], however, there have been still found no effective techniques for biomaterial processing that could solve the problem of bioprosthetic durability. The situation makes it necessary to evaluate a prosthetic tissue condition and determines the necessity to develop new diagnostic methods able to make a quantitative assessment of a prosthetic degradation degree and give a comprehensive idea of a failure development mechanism.

The existing researches on explanted failed bioprostheses rely, chiefly, on macroscopic and histological descriptions [4, 5], these techniques, however, do not give sufficient information on damage structures, the conclusions being qualitative rather than quantitative. High radio-opacity of calcium conglomerates enables to make good use of fluoroscopy to assess calcinosis: in particular, a radiograph enables to provide qualitative imaging of mineralized tissue [6], but gives no chance to give a quantitative evaluation. The most promising methods, which enable to perform

For contacts: Tatiana V. Glushkova, e-mail: bio.tvg@mail.ru 
a quantitative analysis based on three-dimensional reconstructions, are computed tomography techniques [7]. However, due to relatively low resolution of standard CT prevents from reconstructing a detailed structure of calcifications and biological material to the full extent. High resolution of three-dimensional reconstruction can be achieved by microcomputed tomography (micro-CT) considering static research objects, as well as no radiation exposure limits [8]. The approach is widely used when it is necessary to reconstruct precise prosthetic models of heart valves for further computerized modeling [9-11], as well as in biological tissue researches [12]. We suggest using computed tomography to analyze explanted failed prostheses to obtain quantitative characteristics of the impairment under study.

The aim of the investigation was to assess the capabilities of microcomputed tomography with subsequent image analysis of explanted failed biological heart valves prostheses.

\section{Materials and Methods}

Research object. Xenopericardial bioprosthesis UniLine (NeoCor, Kemerovo, Russia) of $30^{\text {th }}$ typical size was chosen as a research object. It refers to a group of rigid stented prostheses, which currently are standard for radical correction of valvular pathologies [13]. A valve itself is made of bovine xenopericardium fixed in glycol
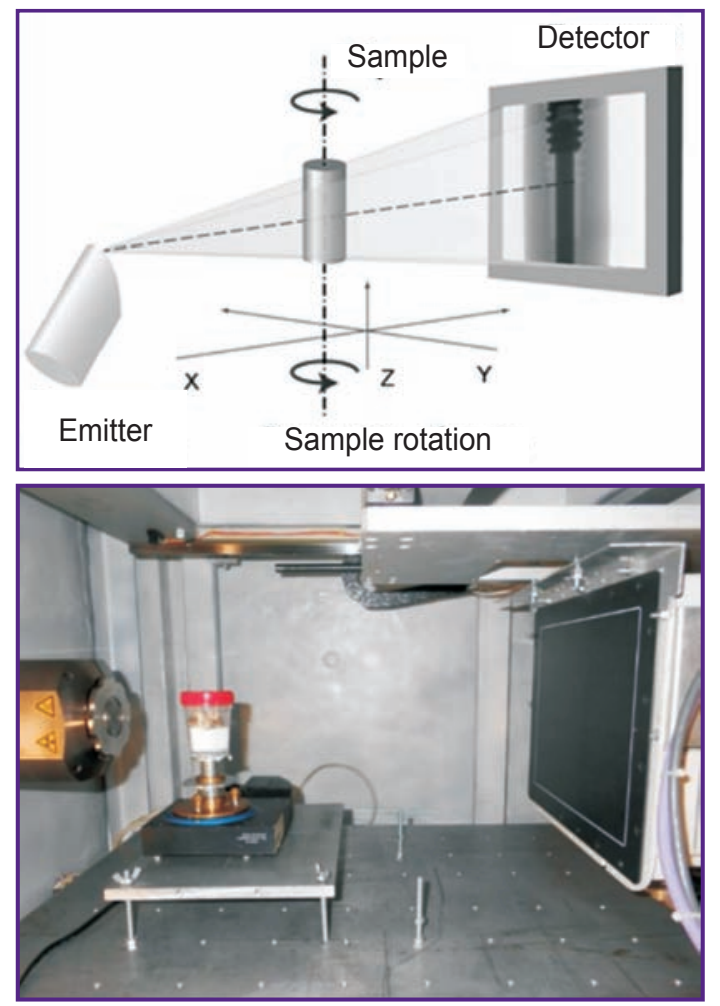

Figure 1. Micro-CT scanning scheme using a conical beam of the fine-focus X-ray apparatus and recording on a flat detector [16], and a tomographic scanner model Orel-MT with the study object diglycidyl ether, mounted on a composite frame made of nitinol and polypropylene. The frame and cuff coating is also made of xenopericardium without synthetic materials $[14,15]$.

The study used a biological valve prosthesis expanded due to a failed mitral position. The patient's age at reprosthesis was 56 years, a prosthesis operation life in the body is 5 years. In order to preserve tissue microstructure after excision the prosthesis was placed in $4 \%$ buffered paraformaldehyde solution (SigmaAldrich, Germany).

Microcomputed tomography. The study was carried out using micro-CT [16]. One of the common schemes of the method is the usage of a radiological apparatus with a small-sized focal spot. A useful beam pattern in the scheme is a cone (Figure 1). Radiation enters through a study object, partially attenuates and is recorded by a flat X-ray detector. The research object is turned through certain degrees round the vertical axis that enables to take radiographs from different views. Voxel size after reconstruction in the scheme is determined by view magnification, which depends on "object-source" and "source-detector" distances [8].

The study involved a tomographic scanner Orel-MT (Tomsk Polytechnic University, Russia) to realize the above-mentioned scheme and showing the following characteristics:

Emitter current: 1-1,000 $\mu \mathrm{A}$;

Voltage: $20-160 \mathrm{kV}$;

Focal spot: $1.3 \mu \mathrm{m}$

Detector: 3 megapixels $(1,920 \times 1,536$ pixels);

14-bit TFT active matrix;

Gain range: $1.3-25.0$;

Scanning area: $150 \times 150 \times 100 \mathrm{~mm}$;

Voxel size: $5-100 \mu \mathrm{m}$.

A tomographic scanner resolution in the experiment was $25.4 \mu \mathrm{m}$. A detector was $500 \mathrm{~mm}$ away from a focal spot, and a research object was at a $100-\mathrm{mm}$ distance. The Table shows the parameters of scanning modes. In order to obtain more contrast and informative images the prosthesis was put in a hermetically sealed container with air.

Subsequent reconstruction of the obtained tomograms, segmentation in accordance with grayscale

\section{Micro-CT parameters of bioprosthesis scanning}

\begin{tabular}{|lcc|}
\hline \multicolumn{1}{|c}{ Parameter } & Mode 1 & Mode 2 \\
\hline Voltage $(\mathrm{kV})$ & 80 & 140 \\
\hline Current $(\mu \mathrm{A})$ & 48 & 23 \\
\hline Frame exposure time $(\mathrm{s})$ & \multicolumn{2}{c}{0.667} \\
\hline Number of frames in a view & 3 \\
\hline Number of views & \multicolumn{2}{c}{1,200} \\
\hline Angular increment (degrees) & \multicolumn{2}{c}{0.3} \\
\hline Voxel size $(\mu \mathrm{m})$ & & 25.4 \\
\hline
\end{tabular}


values, the measurements, as well as the grid were performed using software Mimics (Materialise, USA). When measuring the prosthesis deformities in tomograms corresponding to the planes of histological sections, we recorded the following parameters: $\mathrm{H}$ coaptation zone height, $\alpha-$ angle of deflection of the leaflet, $\mathrm{R}$ leaflet curvature radius, $D-$ frame diameter, $\beta-$ the inclination angle of the prosthesis wire frame rack (Figure 2).

We used software Amira (FEl, USA) for volume rendering and views of maximum intensity and averaged views.

Histological examination. To assess structural changes of the biological material during the prosthesis functioning, we excised the leaflet central part from a free border to the base. Biomaterial microstructure was estimated by light microscopy using the microscope Axio Imager A1 (Carl Zeiss, Germany). Documentation and image processing were performed using software AxioVision (Carl Zeiss, Germany). The biomaterial thickness and calcification sizes were measured on 10 series sections for each sample. Histological specimens, 4-6 $\mu \mathrm{m}$ thick, were prepared on the cryotome Microm HM 525 (Thermo Scientific, Germany).

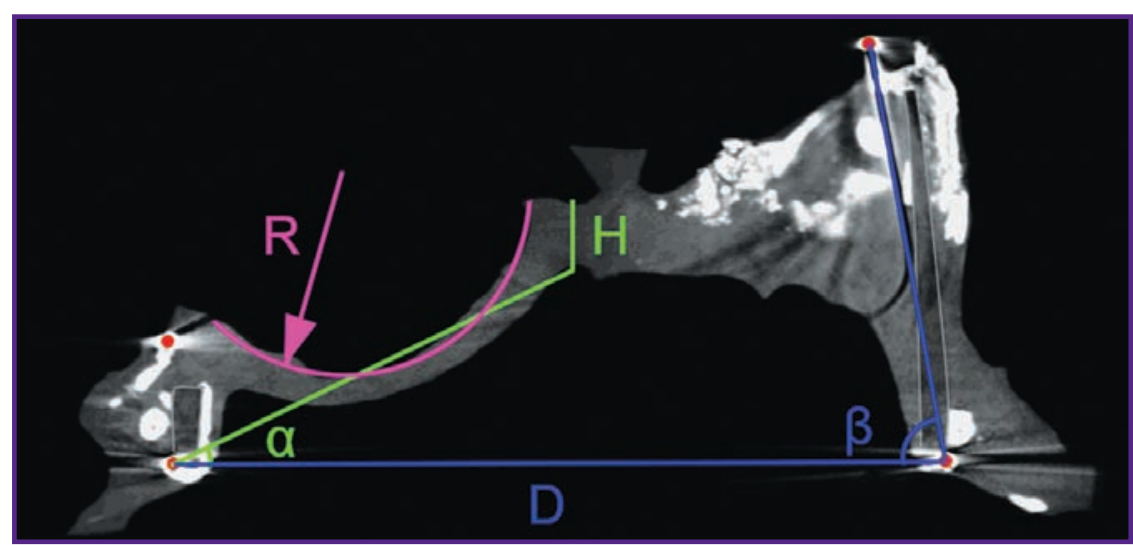

Figure 2. The main parameters measured on the tomograms:

$H$ : coaptation zone height; $\alpha$ : the leaflet deflection angle; $R$ : the leaflet curvature radius; $D$ : the frame diameter; $\beta$ : the inclination angle of the prosthesis wire frame rack

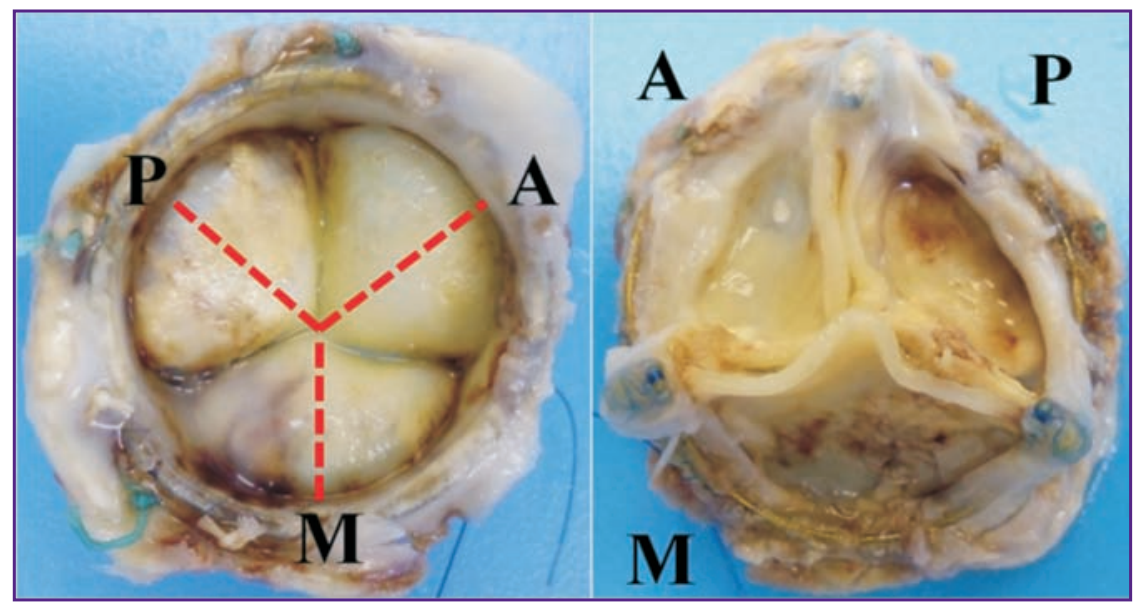

Figure 3. Explanted failed bioprosthesis (the view on the inflow and outflow side):

$A$ : anterior leaflet; $M$ : medial leaflet; $P$ : posterior leaflet; red dot line shows a scheme of histological sections

At microstructural level the cryosections were alizarin red

(Chimsintez, Russia) stained to identify the calcifications.

According to the bioprosthesis position in relation to the natural mitral valve anatomy, we agreed to use the following names for bioprosthetic leaflets: A - anterior, $\mathrm{P}$ - posterior, $\mathrm{M}$ - medial (Figure 3 ).

Statistical analysis. The data were processed according to histological examination findings using Statistica 6.0 (StatSoft Inc., USA). The distribution in sampling was assessed by Kolmogorov-Smirnov test, the data being presented as a median (M), as well as 25 and 75 percentiles.

Results

Microcomputed tomography. Initially, accelerating voltage of an X-ray apparatus was chosen as $80 \mathrm{kV}$. However, under these conditions, typical artifacts appeared on tomograms due to metallic components in a bioprosthesis structure [17]. Voltage was increased up to $140 \mathrm{kV}$ that partly compensated the artifacts;

however, the contrast of the low-absorption components decreased (Figure 4).

The grayscale tomograms and pseudo-color images taken during the experiment demonstrated the main location of the densest calcifications in the tissues of the posterior and medial leaflets, with the anterior leaflet being calcification-free (Figure 5). The calcification thickness in the posterior leaflet dome was $0.92 \mathrm{~mm}$. The medial leaflet had several calcifications in the section located in the leaflet dome and base, maximum thickness being $1.68 \mathrm{~mm}$. The anterior leaflet thickness in the free border was $1.57 \mathrm{~mm}$, in the dome: $1.05 \mathrm{~mm}$.

The medial section (M-section) clearly demonstrated asymmetry of the leaflet free edge, and therefore, the impaired geometry of the coaptation zone: the coaptation zone height was $2.14 \mathrm{~mm}$ versus 3.42 and $3.12 \mathrm{~mm}$ for posterior and anterior leaflets, respectively. 


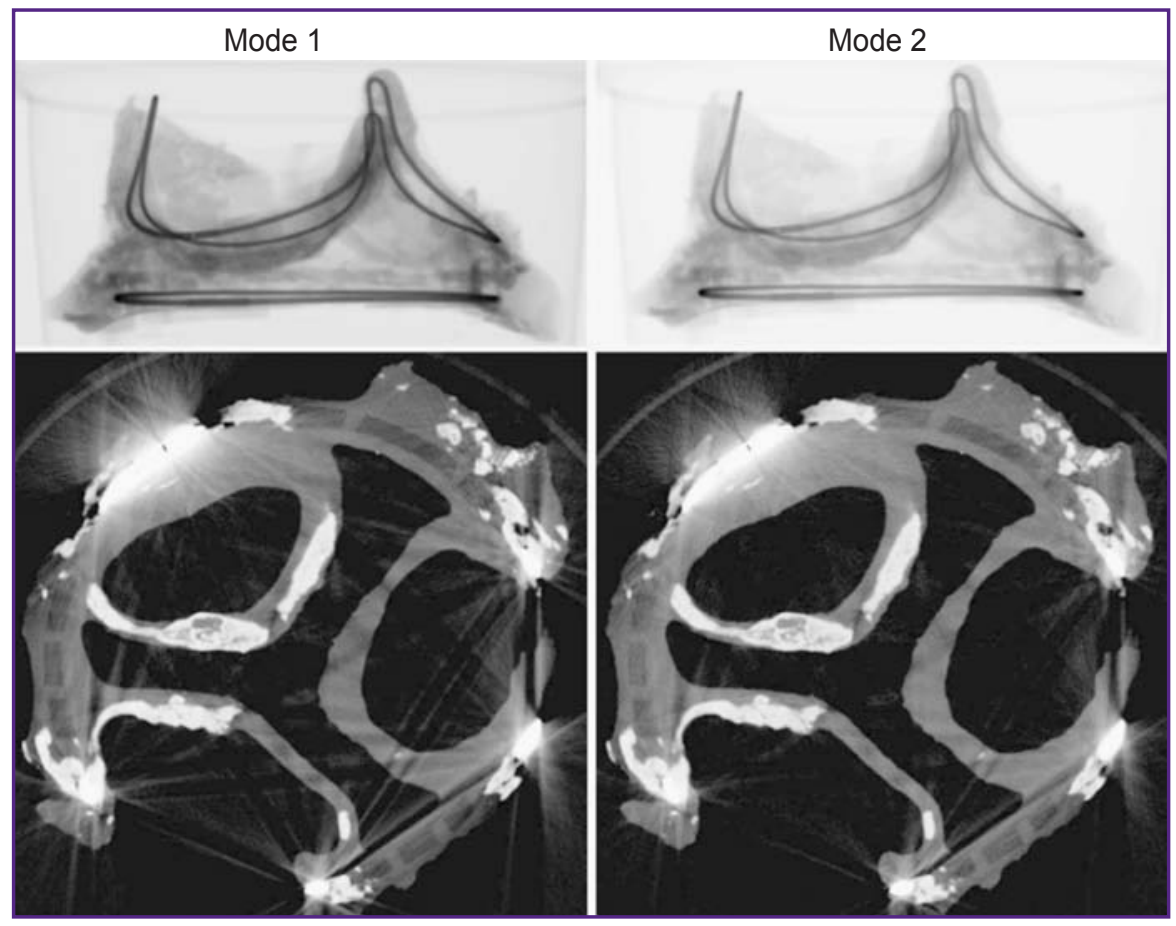

Figure 4. Shadow view of the valve in accelerating voltage of the radiological apparatus $80 \mathrm{kV}$ (mode 1) and $140 \mathrm{kV}$ (mode 2) and corresponding tomograms

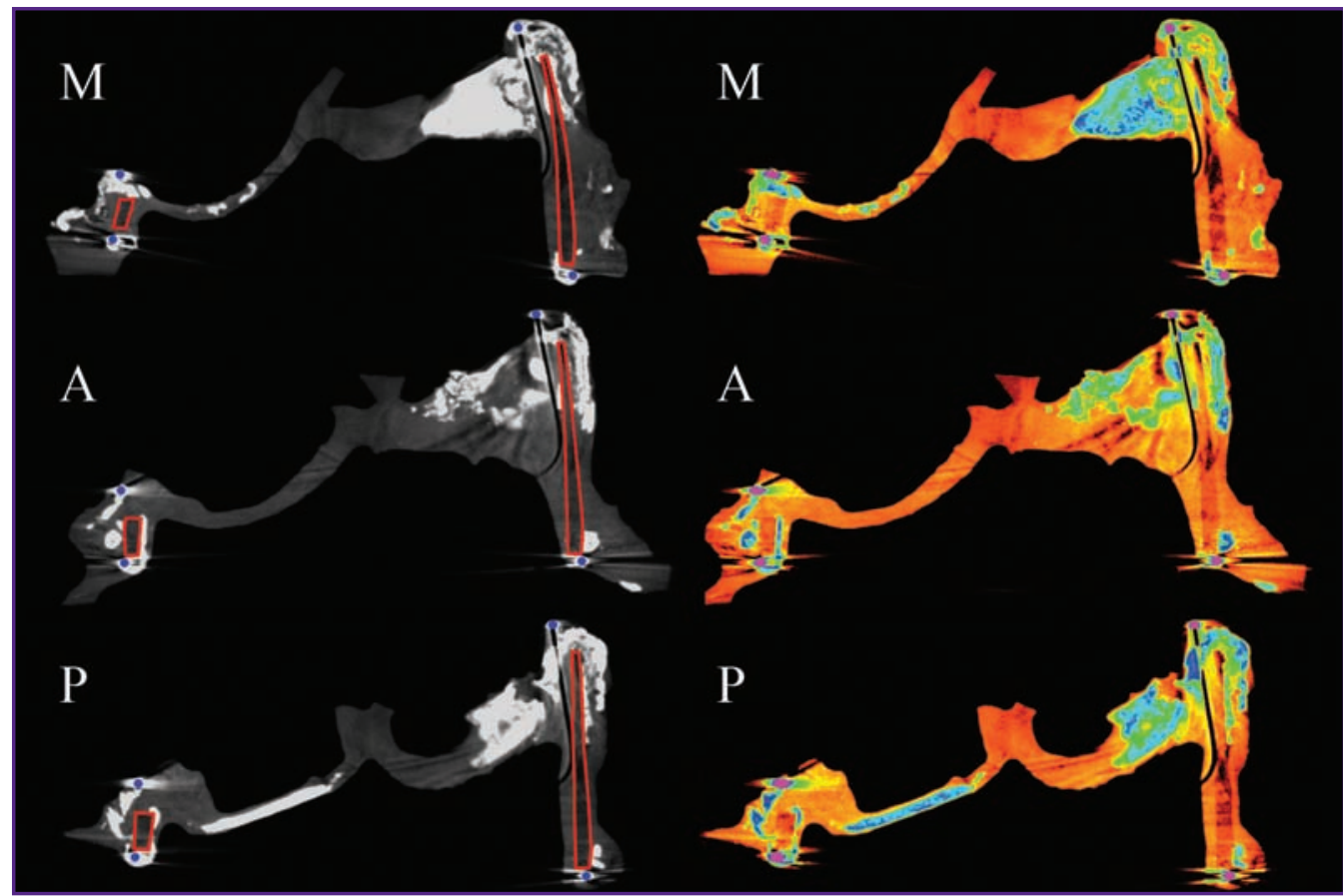

Figure 5. Tomograms corresponding to histological sections and agreed notation of leaflets: $A$ : anterior leaflet; $M$ : medial leaflet; $P$ : posterior leaflet; on black and white films the blue color indicates the contour of a nitinol wire frame, the red color shows the polypropylene frame contour

The least curvature radius in the posterior leaflet was $22.0 \mathrm{~mm}$, the angle of leaflet deflection was $22.7^{\circ}$. The same parameters for the medial and anterior leaflets were $6.15 \mathrm{~mm}, 30.9^{\circ}$ and $7.20 \mathrm{~mm}, 26.0^{\circ}$, respectively.

The posterior-anterior rack of the wire frame had the least inclination angle: $73.4^{\circ}$ (the rack was deformed to the utmost), while the angle of the other racks was nearly the same: $80.0^{\circ}$ (media anterior) and $79.7^{\circ}$ (posterior-medial).

The frame diameter in all three sections slightly deviated from the initial one $-30.48 \mathrm{~mm}$ : 28.96 (P-section), 30.68 (M-section) and $30.22 \mathrm{~mm}$ (A-section), 


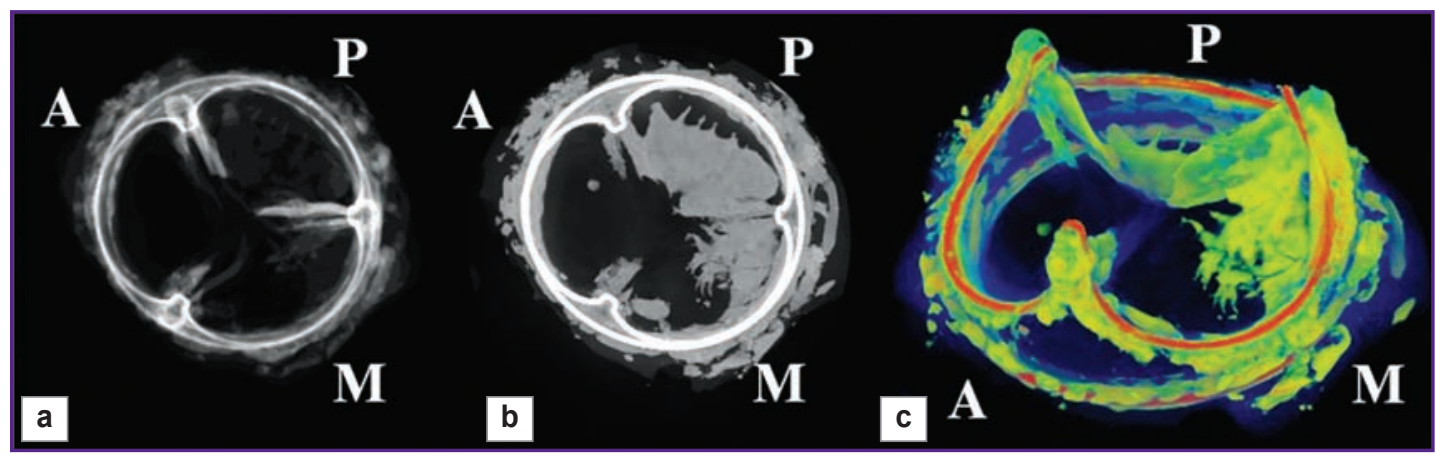

Figure 6. The marked areas with massive calcifications:

(a) using 2-dimensional averaged view; (b) using 2D views of maximum intensity; (c) using 3D false color volume rendering; $A$ : anterior leaflet; $M$ : medial leaflet; $P$ : posterior leaflet

i.e. the frame was not apt to have elliptical deformity (See Figure 5).

The averaged $2 \mathrm{D}$ projection and the maximum intensity projection obtained through the study enabled to distinguish the areas with marked calcinosis (Figure 6). The posterior leaflet underwent the maximum changes, while the medial leaflet was affected on the side of the posterior-medial rack. Moreover, the volume rendering enabled to show clearly the calcifications in the area of the frame racks.

In accordance with the obtained grayscale histogram (16-bit grayscale ranging from 0 to 65,535 ), there were found two main peaks within the range of $800-3,700-$ for biomaterial and polypropylene frame, 3,70010,000 - for calcifications. The range of $10,000-65,535$ corresponded to the wire frame. Segmentation and subsequent 3D models were constructed in accordance with these ranges (Figure 7).

The following values were obtained after measuring the volume of the segmented objects: total calcification volume was $1,499.68 \mathrm{~mm}^{3}$, the wire frame volume was $67.76 \mathrm{~mm}^{3}$, the volume (net of polypropylene frame) was $4,918.5 \mathrm{~mm}^{3}$. Thus, calcium/biological tissue ratio was 0.305 . The total area of calcification network surface was $4,640 \mathrm{~mm}^{2}$.

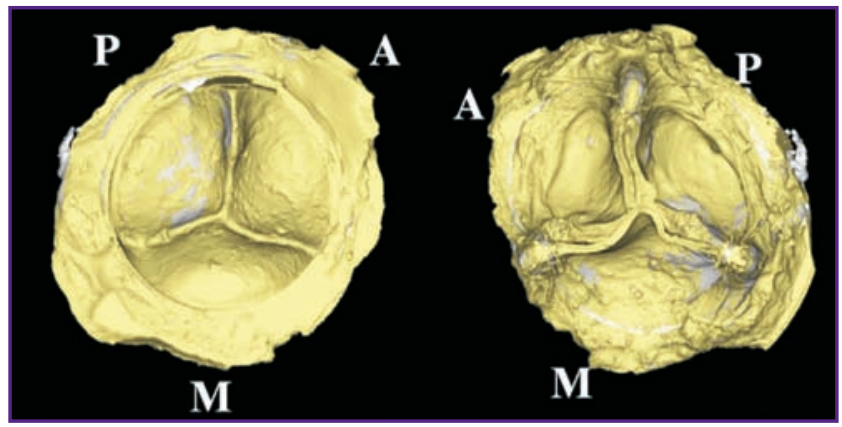

Figure 7. 3D model of a failed heart valve bioprosthesis obtained by micro-CT data reconstruction:

$A$ : anterior leaflet; $M$ : medial leaflet; $P$ : posterior leaflet; yellow color: biological material; white color: calcification

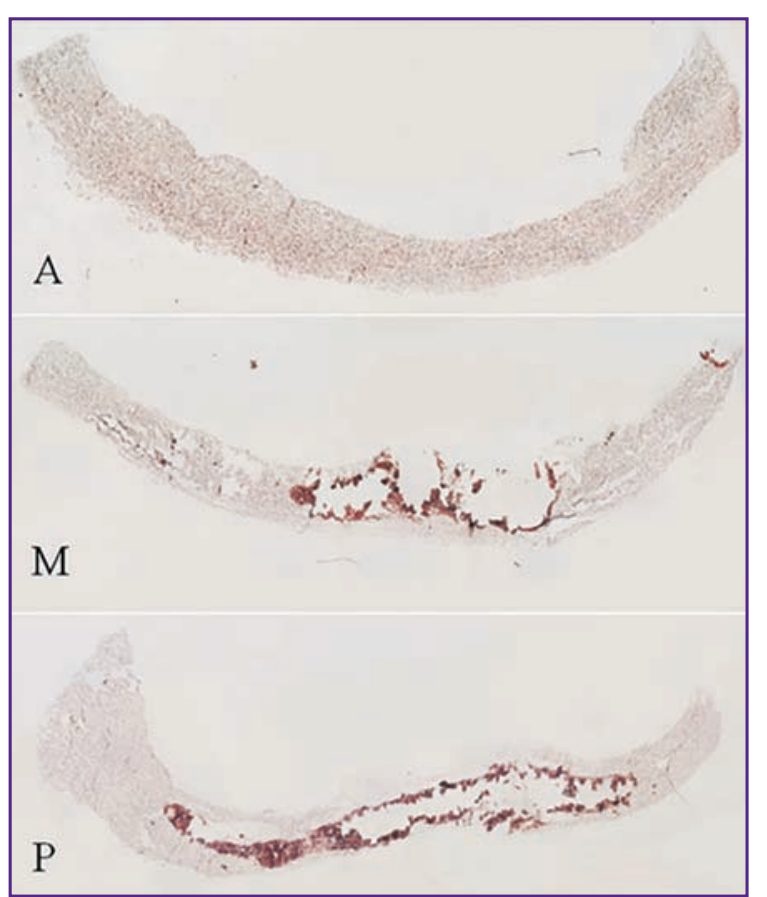

Figure 8. Cryostat sections of bioprosthetic leaflet central part:

$A$ : anterior leaflet; $M$ : medial leaflet; $P$ : posterior leaflet; the free border is to the left, the leaflet base is to the right; the specimen being alizarin red stained; calcification of brown color; $\times 50$

Histological examination. All the leaflets were thickened and lost elasticity. Initial tissue thickness was found to be preserved at the leaflet base. The central part of the posterior and medial leaflets was revealed to have large calcifications, 8.0 and $4.84 \mathrm{~mm}$ in length, respectively, localized in the leaflet dome (Figure 8 ). The maximal thickness of the calcified areas was found in the posterior and medial leaflet dome, it accounting to $0.89(0.88-1.0)$ and $1.64(1.59-1.72) \mathrm{mm}$, respectively. The calcification thickness varied from 0.3 to $0.68 \mathrm{~mm}$. In addition, the calcification was found at the base of the 
medial leaflet attachment to the frame, the calcification having no localization connection with the leaflet dome. The anterior leaflet in the central part had no calcification signs, its thickness in the free edge and the dome was $1.5(1.47-1.54)$ and $0.96(0.94-0.97) \mathrm{mm}$, respectively.

Discussion. The findings of the present research demonstrate that the application of micro-CT in the study of heart valve bioprosthesis dysfunction enables to expand significantly the range of instruments for qualitative and quantitative analyses. In contrast to radiography [6], the technique enables to take views of maximum intensity that can be used for rapid evaluation of calcifications in the leaflet apparatus area (See Figure 6), however, it appears to be ineffective to study the distribution of calcifications along the frame contour due to its complex three-dimensional geometry. 3D false color volume rendering can be successfully applied to solve the problem. Generally, it should be noted that the use of pseudo-color staining, in tomograms, in particular, enables to visualize clearly the prosthesis frame elements with surrounding tissues of similar radiological density (See Figure 5).

The most valuable opportunity among the others micro-CT offers is the quantitative measurement of geometrical parameters on reconstructed tomograms, as well as the reconstruction of three-dimensional models with the subsequent volume rendering. The comparison of the findings of a micro-CT analysis and a histological description showed the data identity. Thus, distortions and artifacts - the major drawback of the method can be considered insignificant.

The measurement findings enable to relate the calcification distribution to stress-strain state of the prosthetic structural nodes. The posterior leaflet had the least curvature radius and the angle of deflection, i.e. it was in the most stressed state, its calcification being marked. It suggests the presence of the correlation between a calcification degree and the tension in the prosthetic leaflet that is consistent with literature data suggesting the material stress to be of primary significance for the calcification rate $[18,19]$. However, the underlying condition of leaflet geometry changes consists in, at least, two factors: a significant asymmetric deformity of the frame racks (initial inclination angle was $84^{\circ}$ ) and the stretching of biological tissue itself under an intensive cyclic load.

The presence of separate calcium conglomerates in leaflets and their following clustering into larger elements is a priority mechanism of forming large accumulations of calcium phosphate crystals [19, 20]. Calcification growth is accompanied by damage and replacement of the organic matrix component for calcium phosphate crystals [20, 21], therefore, the presence of pericardial elements around a large calcification formed suggests internal calcification, when nucleation centers are deep in the material [18]. Significant increase in leaflet thickness in the calcified areas suggests that the replacement process of a biological component by calcifications proceeds intensively due to the calcification growth. However, an increased thickness of a free border of the posterior leaflet and the thickness of the anterior leaflet in whole without calcification signs indicate degenerative changes of biomaterial without a calcification process, the changes also contributing to bioprosthesis dysfunction.

Thus, the present study has clearly shown the capabilities of micro-CT to assess the degree of calcification and deformity alterations of a frame and a leaflet apparatus in failed heart valve bioprostheses.

Conclusion. The suggested method of microCT enables to expand significantly a range of tools to study the development mechanisms of biological prosthesis dysfunction due to quantitative and qualitative assessment of calcification distribution. It enables to carry out batch quantitative processing of the reconstructed models and, in the long term, to solve the problem of their studying by computer modeling techniques.

Study Funding. The study was supported by Research Institute for Complex Issues of Cardiovascular Diseases.

Conflicts of Interest. The authors have no conflicts of interest related to the present study.

\section{References}

1. Bokeriya L.A., Gudkova R.G. Serdechno-sosudistaya khirurgiya - 2015. Bolezni i vrozhdennye anomalii sistemy krovoobrashcheniya [Cardiovascular surgery - 2015 Diseases and congenital anomalies of the circulatory system]. Moscow: NTsSSKh im. A.N. Bakuleva; 2016; 208 p.

2. Hoffmann G., Lutter G., Cremer J. Durability of bioprosthetic cardiac valves. Dtsch Arztebl Int 2008; 105(8): 143-148, https://doi.org/10.3238/arztebl.2008.0143.

3. Zhuravleva I.Y., Veremeyev A.V., Khryachkova O.N., Nikonorova N.G. Disorders of calcium and phosphorus metabolism in patients with acquired heart diseases. Patologiya krovoobrashcheniya i kardiokhirurgiya 2013; 3: 8-12.

4. Siddiqui R.F., Abraham J.R., Butany J. Bioprosthetic heart valves: modes of failure. Histopathology 2009; 55(2): 135-144, https://doi.org/10.1111/j.1365-2559.2008.03190.x.

5. Ong S.H., Mueller R., Iversen S. Early calcific degeneration of a CoreValve transcatheter aortic bioprosthesis. Eur Heart J 2012; 33(5): 586-586, https://doi.org/10.1093/ eurheartj/ehr283

6. Takano T., Terasaki T., Wada Y., Ohashi N., Komatsu K., Fukui D., Amano J. Early bioprosthetic valve calcification with alfacalcidol supplementation. J Cardiothorac Surg 2013; 8(1): 11, https://doi.org/10.1186/1749-8090-8-11.

7. Saleeb S.F., Newburger J.W., Geva T., Baird C.W., Gauvreau K., Padera R.F., Del Nido P.J., Borisuk M.J., Sanders S.P., Mayer J.E. Accelerated degeneration of a bovine pericardial bioprosthetic aortic valve in children and young adults. Circulation 2014; 130(1): 51-60, https://doi.org/10.1161/ circulationaha.114.009835.

8. Batranin A.V., Chakhlov S.V., Grinev D.V., Kapranov B.I., Klimenov V.A. Design of the X-Ray micro- 
CT scanner TOLMI-150-10 and its perspective application in non-destructive evaluation. Applied Mechanics and Materials 2013; 379: 3-10, https://doi.org/10.4028/www.scientific.net/ amm.379.3.

9. Claiborne T.E., Xenos M., Girdhar G., Alemu Y., Sheriff J., Slepian M., Pinchuk L., Jesty J., Einav S., Bluestein D. Dynamic numerical and experimental evaluation of Trileaflet polymer prosthetic heart valves. ASME 2011 Summer Bioengineering Conference 2011; p. 1205-1206, https://doi.org/10.1115/sbc2011-53176.

10. Ovcharenko E.A., Klyshnikov K.U., Yuzhalin A.E., Savrasov G.V., Kokov A.N., Batranin A.V., Ganyukov V.I., Kudryavtseva Y.A. Modeling of transcatheter aortic valve replacement: patient specific vs general approaches based on finite element analysis. Comput Biol Med 2016; 69: 29-36, https://doi.org/10.1016/j.compbiomed.2015.12.001.

11. Ovcharenko E.A., Klyshnikov K.U., Savrasov G.V., Batranin A.V., Ganykov V.I., Kokov A.N., Nushtaev D.V., Dolgov V.Y., Kudryavtseva Y.A., Barbarash L.S. Predicting the outcomes of transcatheter aortic valve prosthesis implantation based on the finite element analysis and microcomputer tomography data. Sovremennye tehnologii v medicine 2016; 8(1): 82-92, https://doi.org/10.17691/stm2016.8.1.11.

12. Liu J., Zhong S., Lan H., Meng X., Zhang H., Fan Y., Wang Y., Wang C., Wang Z. Mapping the calcification of bovine pericardium in rat model by enhanced micro-computed tomography. Biomaterials 2014; 35(29): 8305-8311, https://doi. org/10.1016/j.biomaterials.2014.06.026.

13. Barbarash L.S., Zhuravleva I.Yu. Bioprosthetic heart valve evolution: two decades of advances and challenges. Kompleksnye problemy serdechno-sosudistykh zabolevanii 2012; 1: 4-11.

14. Klyshnikov K.Yu., Ovcharenko E.A., Maltsev D.A., Zhuravleva I.Yu. Comparative characteristics of hydrodynamic data of heart valve bioprostheses "UniLine" and "PeriCor". Klinicheskaya fiziologiya krovoobrashcheniya 2013; 1: 45-51.

15. Karas'kov A.M., Zhuravleva I.lu., Astapov D.A., Stasev A.N., Demidov D.P., Odarenko lu.N., Barbarash L.S. Clinical and hemodynamic results of bioprostheses UniLine using in aortic position. Kardiologiya $i$ serdechno-sosudistaya khirurgiya 2014; 7(4): 87-91.

16. Stock S. Microcomputed tomography. CRC Press; 2008, https://doi.org/10.1201/9781420058772.

17. Kalender W.A. Computed tomography: fundamentals, system technology, image quality, applications. John Wiley \& Sons, 2011; $372 \mathrm{p}$.

18. Pettenazzo E., Deiwick M., Thiene G., Molin G., Glasmacher B., Martignago F., Bottio T., Reul H., Valente M. Dynamic in vitro calcification of bioprosthetic porcine valves: evidence of apatite crystallization. J Thorac Cardiovasc Surg 2001; 121(3): 500-509, https://doi.org/10.1067/ mtc.2001.112464.

19. Halevi R., Hamdan A., Marom G., Mega M., Raanani E., Haj-Ali R. Progressive aortic valve calcification: three-dimensional visualization and biomechanical analysis. J Biomech 2015; 48(3): 489-497, https://doi.org/10.1016/j. jbiomech.2014.12.004.

20. Pukhov D.E., Vasilev S.V., Zotov A.S., Ilin M.V., Rudy A.S. Micromorphology, composition and localization habits of mineral deposits of aortal valves cusps according to the scanning electron microscopy and X-ray diffractometry. Vestnik Natsional'nogo mediko-khirurgicheskogo Tsentra im. N.I. Pirogova 2014; 9(1): 23-30.

21. Cottignoli V., Cavarretta E., Salvador L., Valfré C., Maras A. Morphological and chemical study of pathological deposits in human aortic and mitral valve stenosis: a biomineralogical contribution. Patholog Res Int 2015; 2015: 342984, https://doi.org/10.1155/2015/342984. 